\title{
Drittes Doktorandenseminar der Klebtechnik
}

Am 5. und 6. November 2012 fand zum dritten Mal das Doktorandenseminar Klebtechnik statt. Diesmal folgen insgesamt 13 Doktoranden aus fünf Universitäten sowie zwei Fraunhofer-Instituten gemeinsam mit ihren Professoren und Oberingenieuren der Einladung von Prof. Dr.-Ing. Stefan Böhm (Leiter des Fachgebietes Trennende und Fügende Fertigungsverfahren an der Uni Kassel), um sich im La Strada Hotel in Kassel über aktuelle Forschungsthemen innerhalb der Klebtechnik auszutauschen.

D e Vorträge der Veranstaltung deckten inhaltlich das gesamte Spektrum der Klebtechnik ab. So standen am ersten Tag verschiedene Themen aus den Bereichen Oberflächenbehandlung und Klebstoffchemie sowie über das Fügen von Verbundwerkstoffen auf der Tagesordnung. Hierbei ging es nicht nur um das alterungsbeständige Kleben bzw. das Verhalten des Klebstoffs während der Alterung, sondern es wurde auch über Klebstoffmodifikation, über den Einsatz der Fügetechnik in holzbasierten Multimaterialsystemen und Brennstoffzellen sowie bei textilverstärkten Thermoplasten berichtet. Der zweite Seminar-

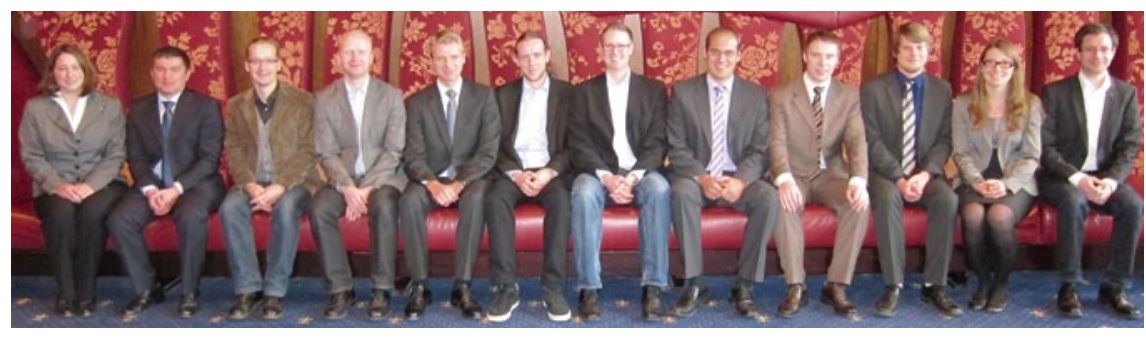

13 Doktoranden kamen gemeinsam mit ihren Professoren und Oberingenieuren auf Einladung von Prof. Dr.-Ing. Stefan Böhm nach Kassel, um sich über aktuelle Forschungsthemen innerhalb der Klebtechnik auszutauschen. tag befasste sich mit den Themenbereichen Klebprozess, klebgerechte Konstruktion sowie Klebstoffverhalten und -funktionalisierung. Näher beleuchtet wurden neben neuen hybriden Prozessen und der Unverzichtbarkeit der Klebtechnik in der E-Mobilität auch das toleranzbedingte Crashverhalten von Klebverbindungen und deren Auslegungsmöglichkeiten für schwingende Belastungen. Den thematischen Abschluss bildeten Ausführungen über Nanokompositklebstoffe und über eine neue Möglichkeit der Massenstrommessung bei hochviskosen Klebstoffen. Die Doktoranden nutzten das Seminar für intensive Diskussionen \section{.}

